\title{
A Proposal for a Geospatial Database to Support Emergency Management
}

\author{
Ivan Frigerio ${ }^{*}$, Stefano Roverato, Mattia De Amicis \\ Department of Earth and Environmental Sciences, University of Milano Bicocca, Milan, Italy \\ Email: *ivan.frigerio@unimib.it
}

Received May 3, 2013; revised June 13, 2013; accepted July 13, 2013

Copyright (C) 2013 Ivan Frigerio et al. This is an open access article distributed under the Creative Commons Attribution License, which permits unrestricted use, distribution, and reproduction in any medium, provided the original work is properly cited.

\begin{abstract}
The basic procedure of the Italian Civil Protection Department aims at reducing disaster losses by giving prominence to a proactive strategy, focusing on prevision and prevention of hazard events rather than postdisater activities. Italian law commits municipalities to produce Emergency Plans that include risk scenarios as well as all data required for emergency management, such as structures, infrastructures and human resources. However the law in the matter of Civil Protection does not supply information about how to produce and archive necessary data for emergency planning and management. For this reason, we propose a standard methodology to create a geodatabase using GIS software, to collect all data that could be used by municipalities to create Emergency Plans. The resulting geodatabase provides a tool for hazard mitigation planning, allowing not only the identification of areas at risk, but also the structures, infrastructures and resources needed to overcome a crisis, thus improving all strategies of risk reduction and the resilience of the system [1].
\end{abstract}

Keywords: Emergency Management; Geospatial Database; Civil Protection; Emergency Planning

\section{Introduction}

Italy is considered a vulnerable country due to the high occurrence of hazardous events and its peculiar geological, geomorphological and climatic conditions. Excessive human activities, illegal constructions and poor environmental maintenance are still increasing natural hazards such as earthquakes, landslides and floods in residential areas. In addition, the presence of holdings that use and produce dangerous substances in industrialized areas, exposes both population and the environment to industrial risk. An accurate knowledge of the incidence of these phenomena (both natural and anthropogenic) is the key to reduce risk, increase resilience and minimize anthropic and environmental damages [2].

The National Civil Protection Department has already developed prevision and prevention plans as well an instruments to identify priority actions in case of necessity: emergency operations linked to hazard events, vulnerable areas and financial resources availability. The role of the Department is to develop Emergency Plans for "expected" events, which may require the intervention of the central organs of the government, whereas the regions

${ }^{*}$ Corresponding author. are responsible for identifying guidelines of Municipal Emergency Plans. This includes mapping the risks in the considered area and identifying the available structures, infrastructures and resources for effective emergency management [3].

As so far, the only document available in Italian country is the "Manuale Operativo" (an Emergency Operations Manual) [4], which represents guidelines to provide Emergency Plans. However it does not specify which mapping elements to consider and how these should be represented in cartography. Consequently, each region adopts its own methodology and it is a lack of a valid standard nationally model.

However, currently, it is quite difficult to create a valid standard model, as all data needed are produced at different institutional levels (national, regional, provincial, municipal) and different scales. On one hand there are policies that provide guidelines to produce data to define maps for environmental planning and in the same time, there are specific directives in order to define the Civil Protection System specifying the methods and the organizations involved in emergency management.

For all the reasons mentioned is strictly necessary to provide national standard, valid over the whole Italian 
territory, in order to obtain precise rules that ensure uniformity of the data to be mapped [5].

\section{Guidelines and Policy of Italian Civil Protection}

The main Italian Civil Protection law (225/92) [6] classify the Civil Protection's tasks in four types: 1) prevision, 2) prevention, 3) rescue and 4) emergency overcome. Among these actions, this law focuses on the development of prevision and prevention activities. This approach is a new cultural orientation based on a systematic and widespread risk analysis in order to reduce the consequences of hazardous events in anthropic areas [7]. In this context, it is necessary to guarantee continuous data exchange between both emergency management and urban planning.

Within the prevention task, the determination of Emergency Plan is the main activity to complete. That is considered as "a set of operating procedures to deal with any expected disaster in a given territory". The aim of Emergency Plan is define event scenarios and elaborate a database to efficiently support emergencies. Thus, the first step in preparing an Emergency Plan is the collection and analysis of spatial data and their mapping at different scales. In this way it is possible to allow not only an overview of the area but also provide a detailed vision on a possible impact of hazardous events on vulnerabilities [8]. So, it is initially necessary to identify and map structures and infrastructures within every municipality, such as roads and strategic buildings (schools, hospital, etc.). Successively, strategic building, parking places and other public constructions have to be classified among three types of emergency areas: 1) rescue and resource areas, 2) population waiting areas and 3) recaption gathering area of the population; even in this case there are thematic symbols for their cartographic representation. For each class, events scenarios must be identified: in particular, possible areas of impact on vulnerable elements must be derived with a detailed scale of at least $1: 10,000$ [9].

In Emergency Plans is also necessary consider, for each risk scenarios identified (hydraulic and hydrogeological, seismic, volcanic, industrial and bushfire), the presence of human resources, material, equipment, as well as operational and decisional capabilities, in order to react very quickly to minimize the damage caused by the occurrence of an hazardous event [10]. A support database for emergency management must therefore contain not only maps, but also all available resources within the area and responsible people for the intervention operations. The expected risk scenarios must then be linked to a precise model of intervention functional to the considered risk, assigning responsibilities for decision-making at different levels, using all resources rationaly and de- fining a communication system that allows a constant information exchange [11]. The plan must be flexible enough to be used in all emergency situations (either expected or unexpected), and simple, in order to be rapidly operative. It also needs to be an easily upgradable document, as it must consider environmental and urban planning changes, as well as the necessity of modifying the extent of an expected risk scenario [12]. Maps are also very important in emergency planning: in fact, the cartography allows a faster and more intuitive knowledge of territory, as well as a better management, both during planning and in the operative phase [13]. In recent years, also the normative recognised the importance digital mapping tools (GIS) for this analysis, in support to traditional paper maps. Even if, as said before, the Plan realized using GIS software is a useful and dynamic tool [14], producing documents that are easily upgradeable [15]. Currently, the use of these technologies is not required by the law, but it is a discretion of individual municipalities.

\section{Regional Contest}

As evidenced by the 225/92 law, each region has developed its own guidelines to assist their municipalities in the preparation of Emergency Plans. In order to understand the state of the art of each region guidelines, a literature search in the archives of 19 Italian regions and Autonomous Provinces of Trento and Bolzano has been carried out. In particular, all local regulations have been considered in order to propose a standard methodology that does not come in conflict with any other existing regional law and that could be easily replicable throughout Italy.

The results show that more than $50 \%$ of the Italian regions are not prepared enough Emergency Planning, thus they leave to municipalities and provinces the freedom to refer only to national guidelines (Table 1).

As evidenced in Table 1, only two Italian regions elaborated in detail Civil Protection laws: Lombardia and Emilia Romagna. In particular, Emilia Romagna Region provided that every municipality and province should organize a own database to support emergency management using Geographic Information Systems. In fact, the main objective of this legislation is creation of digital standardized and geo-referenced database, which all municipalities must take into account when preparing Emergency Plans. The law also evidences the scale at which data should be represented and the topographic maps to be used. It also specifies to use: 1) a point theme to represent the same items shown in the "Manuale Operativo" (Emergency Area and Coordination Centres), 2) a linear theme to represent administrative boundaries, transport infrastructure and technological networks and 3) a polygon theme to represent the event scenarios. 
Table 1. List of provisions of low about emergency planning for each Italian region.

\begin{tabular}{|c|c|}
\hline Region & Regulation \\
\hline Abruzzo & National \\
\hline Basilicata & National \\
\hline Calabria & D.g.r. $472 / 2007$ \\
\hline Campania & National \\
\hline Emilia Romagna & D.g.r. 1166/2004 \\
\hline Friuli Venezia Giulia & National \\
\hline Lazio & National \\
\hline Liguria & D.g.r. $746 / 2007$ \\
\hline Lombardia & L.r. 16/2004 \\
\hline Marche & National \\
\hline Molise & National \\
\hline Piemonte & D.g.r. $42 / 2004$ \\
\hline Puglia & National \\
\hline Sardegna & National \\
\hline Sicilia & D.g.r. 2/2011 \\
\hline Toscana & D.g.r. $26 / 2000$ \\
\hline Umbria & National \\
\hline Valle d'Aosta & National \\
\hline Veneto & National \\
\hline Prov. Trento & L.p. $9 / 2011$ \\
\hline Prov. Bolzano & Guidelines 2009 \\
\hline
\end{tabular}

On the other hand, the guidelines issued by the Lombardy Region through the DGR n.8/4732 ("Direttiva Regionale per la pianificazione di emergenza degli enti locali" of 16 may 2007) [16], discipline how to draw up Emergency Plans, but it does not constrain to use informatics tools. In particular, it indicates how to map these elements, from spatial data (such as structures and infrastructures) to event scenarios and expects the use of GIS software to generate the Emergency Plan [17]. In this perspective, the Lombardy Region developed a standard web oriented methodology, called PEWEB, which aims to create a regional spatial database in order to share data of every municipality and therefore to effectively manage emergency planning. The PEWEB system requires spatial data in shapefile format to be loaded instead tabular data has to send in XLM format. Data are divided into 5 categories: 1) risk areas, 2) strategic structures, 3) strategic areas, 4) point of accessibility and 5) road network infrastructure. Each category is composed by a unique geometry and are identified by specific codes. Table 2
Table 2. Example of the category risk areas that represent the event scenarios. The field "type of risk" describes the typology of risk that must be mapped within the municipality. Instead, the field "type of hazardous event" contains a description of the type of risk considered. In addition, each item is identified by a unique identification code.

\begin{tabular}{|c|c|c|c|}
\hline \multicolumn{2}{|r|}{ Type of risk } & \multicolumn{2}{|r|}{ Type of hazardous event } \\
\hline Code & Description & Code & Description \\
\hline 0 & Other & -1 & $\begin{array}{l}\text { Value to be assigned } \\
\text { as the default }\end{array}$ \\
\hline \multirow{10}{*}{1} & \multirow{10}{*}{$\begin{array}{l}\text { Hydrogeological } \\
\text { risk }\end{array}$} & 0 & Other \\
\hline & & 1 & Landslide surface \\
\hline & & 2 & Topple \\
\hline & & 3 & Rockfall \\
\hline & & 4 & Debris flow \\
\hline & & 5 & $\begin{array}{c}\text { Bank erosion of } \\
\text { hydrographic network }\end{array}$ \\
\hline & & 6 & Flooding of the minor rivers \\
\hline & & 7 & $\begin{array}{l}\text { Flooding of the major rivers } \\
\text { (PAI zones) }\end{array}$ \\
\hline & & 8 & Flooding of the lakes \\
\hline & & 9 & Avalanche \\
\hline \multirow{2}{*}{2} & \multirow{2}{*}{ Seismic risk } & 0 & Other \\
\hline & & 1 & Earthquake \\
\hline \multirow{4}{*}{3} & \multirow{4}{*}{ Bushfire risk } & 0 & Other \\
\hline & & 1 & Bushfire on forested area \\
\hline & & 2 & Bushfire on urbanized area \\
\hline & & 3 & Bushfire on infrastructure \\
\hline \multirow{7}{*}{4} & \multirow{7}{*}{ Industrial risk } & 0 & Other \\
\hline & & 1 & Productive plant \\
\hline & & 2 & $\begin{array}{l}\text { Burst-productive plant } \\
\text { explosion }\end{array}$ \\
\hline & & 3 & $\begin{array}{c}\text { Gaseous emissions into the } \\
\text { atmosphere }\end{array}$ \\
\hline & & 4 & $\begin{array}{l}\text { Dispersion of toxic or } \\
\text { harmful liquid }\end{array}$ \\
\hline & & 5 & $\begin{array}{c}\text { Emission of radioactive, toxic } \\
\text { or harmful materials }\end{array}$ \\
\hline & & 6 & $\begin{array}{l}\text { Incident to transport } \\
\text { dangerous substances }\end{array}$ \\
\hline \multirow{4}{*}{5} & \multirow{4}{*}{ Environmental risk } & 0 & Other \\
\hline & & 1 & Tornado \\
\hline & & 2 & Hailstorm \\
\hline & & 3 & Water crisis \\
\hline
\end{tabular}


show the example of the category "risk areas". All categories have point geometry, with the exception of the first one ("risk areas"), that is a polygonal one.

The category "strategic structure" is referred to buildings or built-up areas, while "strategic area" identifies open areas that can be used as logistic bases for the rescuers, resources and materials, or as zones able to receive a great number of people in case of emergency. The category "point of accessibility" identifies structures finalized to the movement of vehicles, materials and people such as railway stations and airports. Finally, the category "road network infrastructure" is referred to significant infrastructures for the viability such as bridges, viaducts and overpasses [18].

\section{Proposal for a Geo-Referenced Spatial Database to Support Emergency Management}

The classification adopted by Lombardy Region through the PEWEB system is the most complete and systematic among those analyzed, but it is not entirely exhaustive because it does not include all elements the National Operating Manual recommends for Emergency Plans mapping. However, it was decided to use this system, with the required changes and additions, as the basis for the elaboration of a new classifying proposal of the geo-referenced spatial database. In fact, the PEWEB system has a well good organized and items classification clearly reflect guidelines. For this purpose, it was necessary to define a new taxonomy at national level, to be used as the basis for the creation of the territorial geo-referenced database that should consider the elements to be mapped in a logical and functional way. This item was grouped into eight categories with a specific geometry (Table 3):

Each category also contains several classes with different objects, refered to the final elements to be mapped. Among the objects of each class it was included the item "Other" to denote generic elements that can not be classified by the current items. For example, in Table 4, the

Table 3. The eight category of the proposed taxonomy.

\begin{tabular}{cc}
\hline Category & Type of geometry \\
\hline Area at risk & Polygon \\
Strategical surface & \\
Generic facility & Point \\
Operative strategic structure & \\
Ron operative strategic structure & \\
\hline Point of access & Line \\
\hline Technological networks and infrastructure & \\
\hline
\end{tabular}

Table 4. Classification proposal: category operative strategic structure. The classes that bring together the different elements to be mapped are identified by a unique code: 11: Institutional head office, 12: Head of operating structure, 13: Head of the emergency management center, 14: Emergency facility.

\begin{tabular}{|c|c|c|c|}
\hline & Class & & Objects \\
\hline Code & Description & Code & Description \\
\hline \multirow{7}{*}{11} & \multirow{7}{*}{$\begin{array}{l}\text { Institutional } \\
\text { head office }\end{array}$} & 0 & Other \\
\hline & & 1 & Municipality \\
\hline & & 2 & Prefecture \\
\hline & & 3 & Province \\
\hline & & 4 & Region \\
\hline & & 5 & Consortium Park Authority \\
\hline & & 6 & Mountain Communities \\
\hline \multirow{13}{*}{12} & \multirow{13}{*}{$\begin{array}{l}\text { Head of operating } \\
\text { structure }\end{array}$} & 0 & Other \\
\hline & & 1 & Fire Department \\
\hline & & 2 & SSUEM-118 \\
\hline & & 3 & Red Cross \\
\hline & & 4 & Military \\
\hline & & 5 & Police District Department \\
\hline & & 6 & $\begin{array}{l}\text { Voluntary of Civil } \\
\text { Protection }\end{array}$ \\
\hline & & 7 & $\begin{array}{l}\text { Emergency Multipurpose } \\
\text { Centers }\end{array}$ \\
\hline & & 8 & Municipal Warehouses \\
\hline & & 9 & State Forest Management \\
\hline & & 10 & $\begin{array}{l}\text { Carabinieri District } \\
\text { Department }\end{array}$ \\
\hline & & 11 & Police State \\
\hline & & 12 & $\begin{array}{c}\text { Alpine and } \\
\text { Speleological Rescue }\end{array}$ \\
\hline \multirow{5}{*}{13} & \multirow{5}{*}{$\begin{array}{l}\text { Head of the } \\
\text { emergency } \\
\text { management } \\
\text { center }\end{array}$} & 0 & Other \\
\hline & & 1 & Rescue Coordination Center \\
\hline & & 2 & $\mathrm{COM}$ \\
\hline & & 3 & $\mathrm{COC}$ \\
\hline & & 4 & UCL \\
\hline \multirow{4}{*}{14} & \multirow{4}{*}{ Emergency facility } & 0 & Other \\
\hline & & 1 & $\begin{array}{l}\text { Reception Center } \\
\text { and Shelter }\end{array}$ \\
\hline & & 2 & $\begin{array}{l}\text { Suitable Structure for } \\
\text { Operational Centers }\end{array}$ \\
\hline & & 3 & Health Care Facility \\
\hline
\end{tabular}


category "Operative Strategic Structure", identified by a punctual geometry, includes four classes that represent the basic structures to be activated in case of emergency (Figure 1). In total, in all eight categories studied, 138 items (grouped in 38 classes) were identified, with the exclusion of items classified as "Other".

Once processed this new taxonomy, the next step was to create a digital geo-referenced database. It was decided to organize the data using a relational database, in which tables without duplicate rows represent all data: therefore, a suitable key uniquely identifies a row.

In this structure, the user is also able to query the system with complex requests, crossing data from different tables. It is however necessary to include a common key field ("key") in all tables allowing the combining of information from one table to another. Therefore, it is possible to consider the same object at the same time from different points of view (e.g. chronological, regulatory, typology, etc.); instead, in hierarchical database only one type of interdependence between objects is possible [19]. It was also created the domain, an outstanding part of the geodatabase, which contains all possible values assigned to a field. The domain has been applied to the field "Code" that specifies the type of identified object. With this structure, the user will be constrained to choose among different elements of a list: their priority is specified in the guidelines of the Operations Manual. For example, in the class "Emergency facility", the user can choose among reception centers and shelters, suitable structures for operational centers or health care facilities. It is therefore guaranteed the representation of the classes identified, avoiding the possibility of mapping structures at will, leaving so the proposed standard of the Operations Manual.

It should be remembered, however, that for each class there is always the generic field "Other" that allows the classification of not provided items.

In this project, the geodatabase has been completed using ESRI ArcGIS 10.1, but it is also possible to use other database format such as PostgreSQL with PostGIS extension for geospatial data. Afterwards, the geodatabase has been divided into feature dataset, each containing the feature classes identified in the proposed taxonomy. For each feature class, descriptive fields (the same provided in the proposed taxonomy) were then assigned. These fields will be the same that appear in the representation of the elements in the cartography. It was used "short integer" format for integer numbers, "float" for decimal numbers and "text" for alphanumeric strings (Table 5). The field "text" was also used for the fields

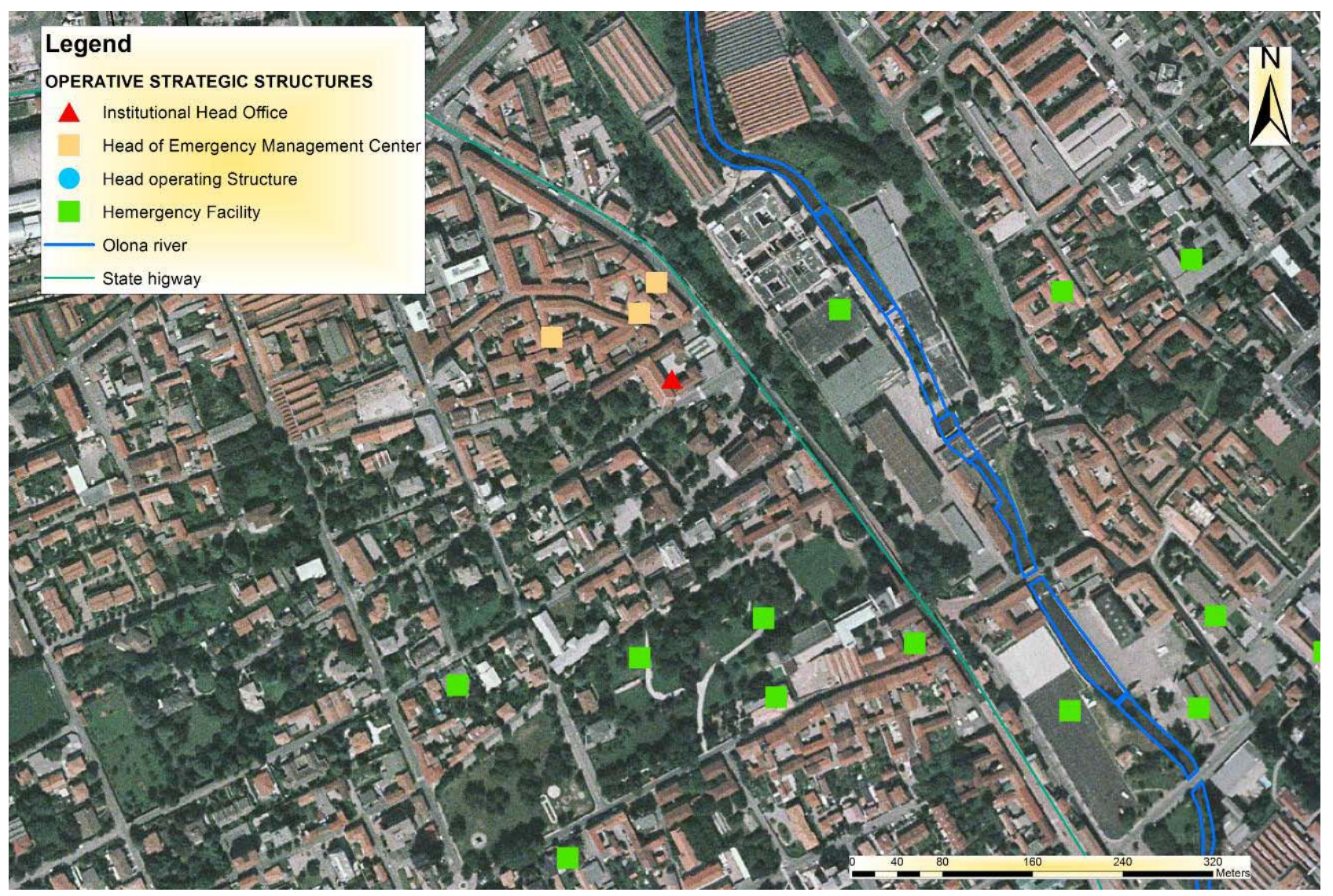

Figure 1. Example of strategic operative structure in Castellanza town (in the province of Varese, Italy). 
Table 5. Fields about feature class of "emergency facility".

\begin{tabular}{cc}
\hline Field name & Data type \\
\hline Shape & Geometry \\
Code & Short integer \\
Address & Text \\
Municipality Code & Text \\
Number of floors & Short integer \\
Surface area & Float \\
Number of sleeping accomodation & Short integer \\
Type of use & Text \\
Vulnerable & Text
\end{tabular}

true/false, associating it to a domain in which two of the values "0-No", "1-Yes" were included, for example the field "Vulnerable". In addition, to improve the interoperability of the data, coordinates in the geographic reference system WGS84 were assigned to all feature classes. In the future, the use of a geo-database to compile Civil Protection Plans will be easier and more convenient in order to organize all information needed. The adoption of a standard method will also allow faster information exchange between various administrations, considering not only different Regions, but entire Italy: this would lead to planning simplification and allow to easily manage emergencies.

\section{Test the Geo-Database on a Real Case}

The geo-database has been tested on a real case, using data of Castellanza town (province of Varese), in order to assess the effectiveness of the developed database.

First of all, the spatial data in shapefile format were prepared for import, to be compatible with the new adopted taxonomy. In particular, a numeric field called "Code" was added to each attribute table of the shapefile: this has the same values used in the taxonomy table, part of which is shown in Table 6. It was then possible to import the records of the shapefile representing Castellanza territorial data in the feature classes, organized according to considered fields. This operation has been performed for all classes of structures identified and the results were loaded into the geodatabase, as shown in Table 6. During this operation, emerged a critical situation regarding "Strategical surface" feature class: in fact, the geodatabase, which was structured to use polygonal geometries, conflicted with Castellanza available punctual data. This prevented data loading. This problem emphasizes the need of a standard methodology that could bring the users to collect and store all data in polygon shapefile format.
Table 6. Classes of the structure, type and numbers of elements present in Castellanza town.

\begin{tabular}{|c|c|}
\hline Structure & $\begin{array}{c}\text { Number and type of objects } \\
\text { in Castellanza town }\end{array}$ \\
\hline Crowd aggregation center & 3 trade center and 3 sport centre \\
\hline School & $\begin{array}{l}1 \text { university, } 3 \text { nursery school } \\
\text { and } 8 \text { schools }\end{array}$ \\
\hline Industrial plant & 215 production \\
\hline Industrial plant at risk & $\begin{array}{c}4 \text { plant of the following industries: } \\
\text { Agrolinz, Melamin, Cisalpina } \\
\text { and Perstrorp }\end{array}$ \\
\hline Place of worship & 3 churches \\
\hline Health facility & $\begin{array}{l}2 \text { hospital, } 4 \text { pharmacies } \\
\text { and } 1 \text { private hospital }\end{array}$ \\
\hline Accommodation & 2 hotels \\
\hline Road network infrastructure & 4 viaducts and 13 crossing roadway \\
\hline Point of access & $\begin{array}{l}2 \text { rail station and } 1 \text { helicopter } \\
\text { landing pad }\end{array}$ \\
\hline Power plant & $\begin{array}{c}84 \text { high pylons and } \\
52 \text { electrical box (other) }\end{array}$ \\
\hline Institutional head office & Municipality \\
\hline Emergency facility & $\begin{array}{l}2 \text { health care facility and } \\
18 \text { rescue and resource structure }\end{array}$ \\
\hline Head of operating structure & Carabinieri \\
\hline $\begin{array}{l}\text { Head of the emergency } \\
\text { management center }\end{array}$ & $3 \mathrm{COM}$ \\
\hline $\begin{array}{l}\text { Framework for } \\
\text { telecommunications }\end{array}$ & 9 antenna tower for mobile \\
\hline Materials warehouse & 14 gas station \\
\hline Structure of bushfire interest & $\begin{array}{l}29 \text { point of water supply, } \\
199 \text { hydrants and } 6 \text { well }\end{array}$ \\
\hline
\end{tabular}

With relation to the risks, this municipality is subject to three different types of events: 1) flooding risk (of the river Olona), 2) buschfire risk and 3) industrial risk (Figures 2 and 3). These data have been loaded in the geodatabase using the same procedure described for the structures. The linear shapefile, referred to both "infrastructure networks" and "technological networks". This refers to provincial and state roads, railways, mains supply, electricity and sewer distribution over the Castellanza territory were lastly loaded.

\section{Conclusion}

The analysis described in this paper was conducted to respond to the absence of Italian standard methodology in order to identify, analyze and archive data to be used for the development of local Emergency Plans. The results of the first part of this work emphasize the frag- 


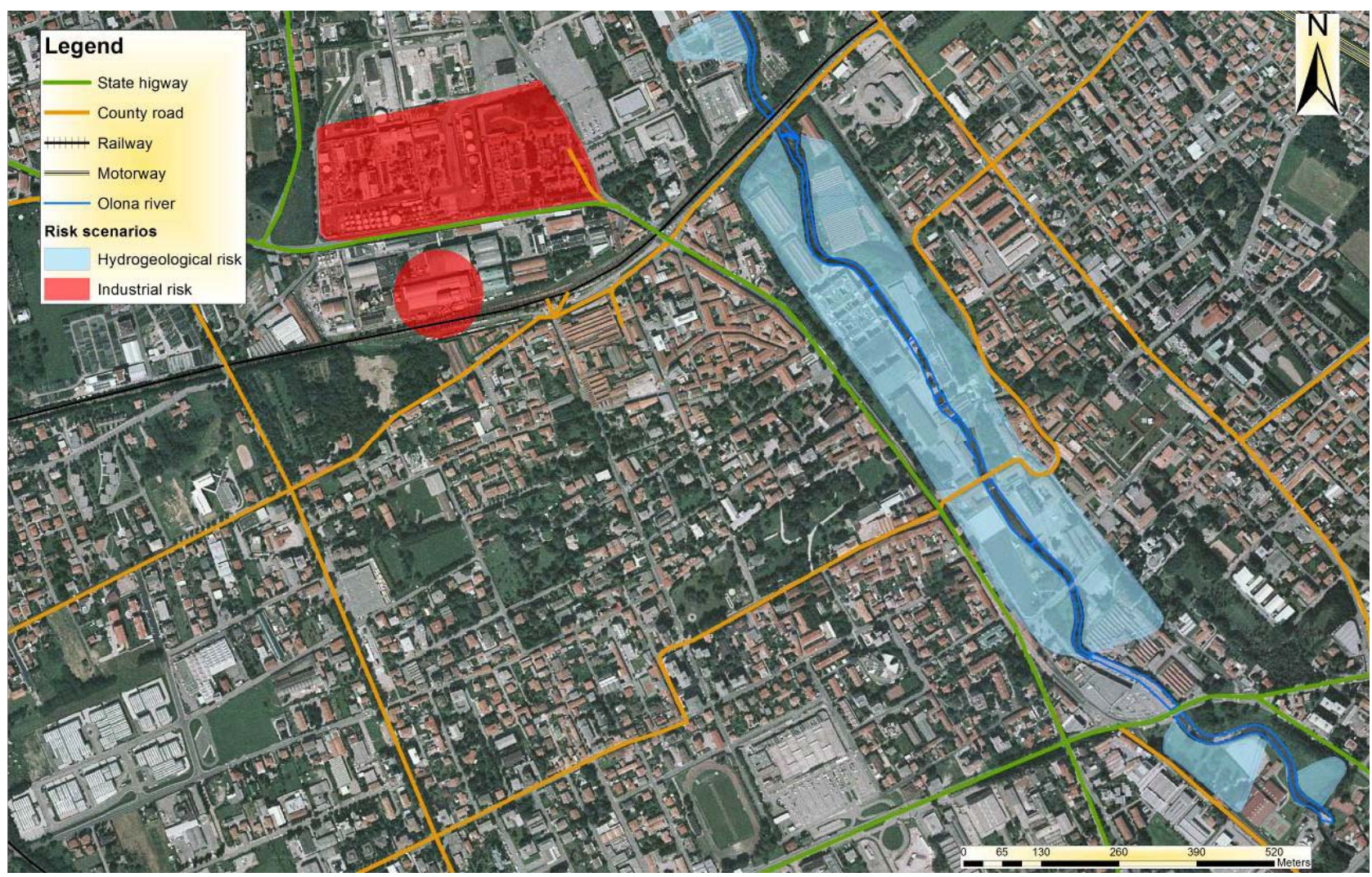

Figure 2. Hydrogeological and industrial risk scenarios.

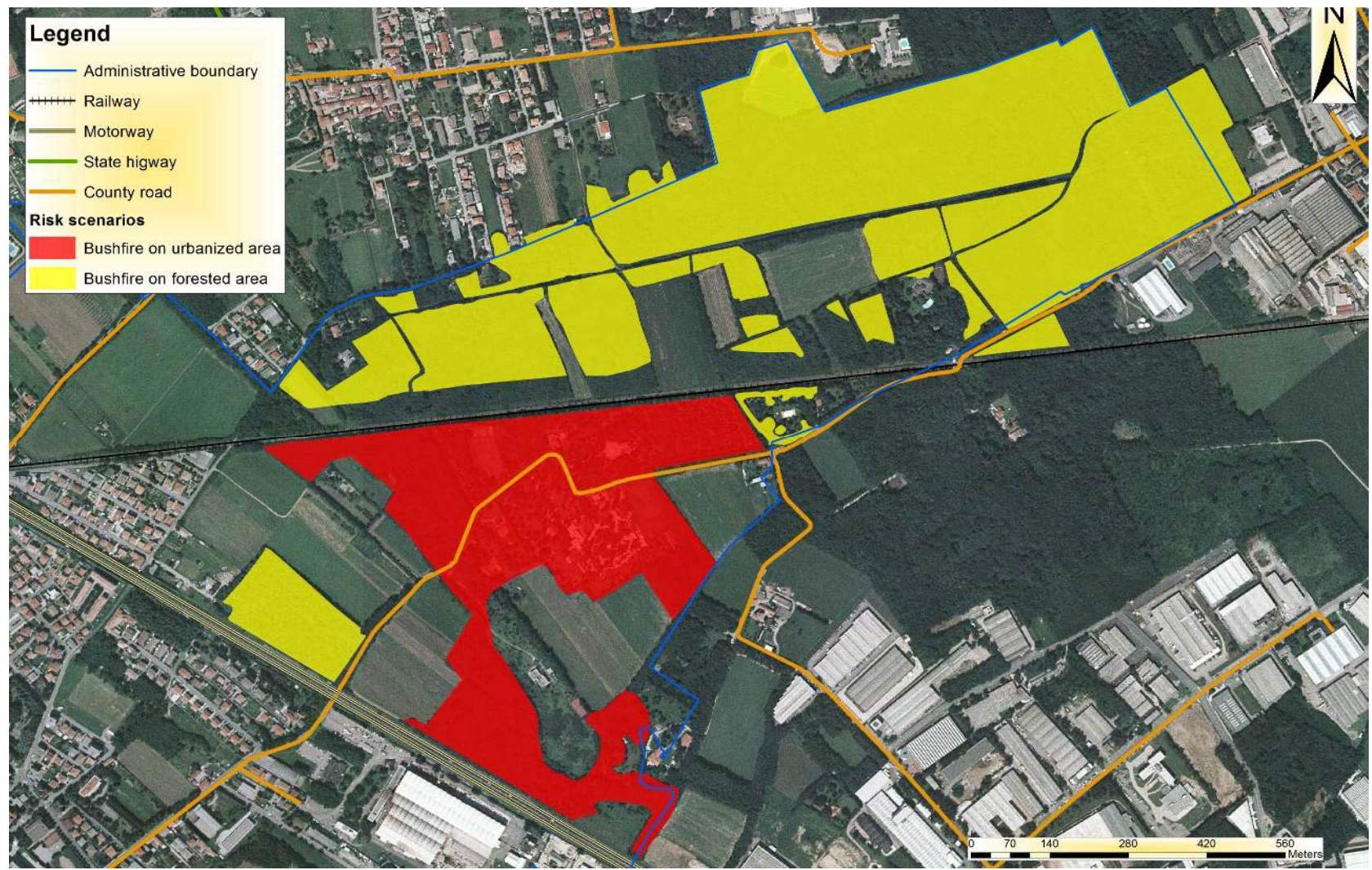

Figure 3. Bushfire risk scenarios. 
mented framework of Italy. The Regions that show interest in this issue are few: only Lombardy and Emilia Romagna Regions, in fact, implemented solutions to overcome this problem by adopting a specific system, as the PEWEB system for Lombardy. This problem is due to the absence of a national law that imposes to municipalities which data use for Emergency Plans and where to find them. The result is that, actual needed data are mainly produced either by urban planning or by specific directives linked to the definition of the Civil Protection System which refers to emergency planning, and these two systems do not interact. The presented analysis attempts to close this gap, proposing a standard methodology to uniform the input data so as to increase their interoperability. The GIS techniques, implemented to create geodatabase, are not overly complex and required input data is easily available to the most public administrations. The development of these procedures made a breakthrough towards the unification of the systems of emergency management of Civil Protection on a national scale. The described procedure revealed to be highly flexible and simple, two features those are at the base of emergency planning. The system was tested only in one municipality (Castellanza), from which some critical points emerged, even if the global evaluation of the proposed methodology is highly positive. This test underscores the necessity, in the near future, to test this geodatabase on a great number of municipalities in order to highlight other gaps or problems, to develop a precise and efficient methodology, improving therefore emergency planning and management throughout the whole Italian country.

\section{REFERENCES}

[1] S. L. Cutter, "GI Science, Disaster and Emergency Management," Transactions in GIS, Vol. 7, No. 4, 2003, pp. 439-446. doi:10.1111/1467-9671.00157

[2] J. Birkmann, "Measuring Vulnerability to Natural Hazards: Towards Disaster Resilient Societies," United Nations University Press, New York, 2006.

[3] S. L. Cutter, C. T. Emrich, B. J. Adams, C. K. Huyck and R. T. Eguchi, "New Information Technologies in Emergency Management," In: W. I. Waugh and K. Tierney, Eds., Emergency Management: Priciples and Practice for Local Governement, International City/Country Management Association (ICMA) Press, 2007.

[4] Dipartimento di Protezione Civile, "Manuale Operativo per la Predisposizione di un Piano Comunale o Intercomunale di Protezione Civile," 2007.

[5] D. Alexander, "Towards the Development of a Standard in Emergency Planning," Disaster Prevention and Management, Vol. 14, No. 2, 2005, pp. 158-175. doi:10.1108/09653560510595164

[6] Law 225/92, "Istituzione del Servizio Nazionale di Protezione Civile".

[7] S. L. Cutter, E. Tate and M. Berry, "Integrated Multiazard Mapping," Environmental and Planning B: Planning and Design, Vol. 37, No. 4, 2010, pp. 646-663.

[8] J. Blauth, I. Poretti, M. De Amicis and S. Sterlacchini, "Database of Geo-Hydrological Disaster for Civil Protection Purposes," Natural Hazard, Vol. 60, No. 3, 2012, pp. 1065-1083.

[9] T. J. Cova, "GIS in emergency management," 1999.

[10] J. R. Jensen and M. E. Hodgson, "Remote Sensing of Natural and Man-Made Hazards and Disasters," In: M. K. Ridd and J. D. Hipple, Eds., Manual of Remote Sensing: Remote Sensing of Human Settlements, American Society for Photogrammetry and Remote Sensing, 2006, pp. 401429.

[11] A. Cavallin, S. Sterlacchini, I. Frigerio and S. Frigerio, "GIS Techniques and Decision Support System to Reduce Landslide Risk: The Case Study of Corvara in Badia, Northern Italy," Geografia Fisica e Dinamica Quaternaria, Vol. 34, 2011, pp. 81-88.

[12] D. Alexander, "Principles of Emergency Planning and Management," Terra Publishing, 2002.

[13] P. A. Longley, M. F. Goodchild, D. J. Maguire and D. W. Rhind, "Geographic Information System and Science," John Wiley and Sons, Hoboken, 2005.

[14] National Research Council, "Successful Response Starts with a Map: Improving Geospatial Support for Disaster Management," National Academies Press, Washington DC, 2007.

[15] M. Konecny, S. Zlatanova and T. L. Bandrova, "Geographic Information and Cartography for Risk and Crisis Management," Springer, Berlin, 2010.

[16] Regione Lombardia, "Direttiva Regionale per la Pianificazione dell'Emergenza Degli Enti Locali," Bollettino Ufficiale della Regione Lombardia, Milano, 2007.

[17] Dipartimento di Protezione Civile-Presidenza del Consiglio dei Ministri, "Metodo Augustus," DPC Informa, No. 12, 1997.

[18] Regione Lombardia, "GEODB Prevenzione e Sicurezza, Sintesi Progettazione Esterna e Specifiche Funzionali. Architettura Informativa. Mosaico Piani di Emergenza," Bollettino Ufficiale della Regione Lombardia, Milano, 2011.

[19] S. Sumathi and S. Esakkirajan, "Fundamentals of Relational Database Management System," Springer Science and Buisness Media, Vol. 47, 2007. doi:10.1007/978-3-540-48399-1 